\title{
A Rare Cause of May-Thurner Syndrome Postarterial Intervention
}

\author{
Hiok Yang Chan ${ }^{1}$ Edward Tieng Chek Choke ${ }^{2} \quad$ Tjun Yip Tang ${ }^{2}$ Chandramohan Sivanathan \\ Chua Ming Er Jasmine ${ }^{1}$ Pradesh Kumar ${ }^{1}$
}

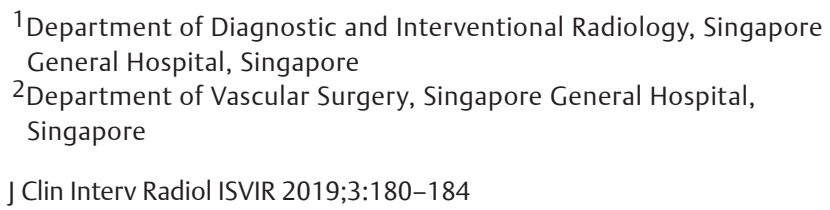

Address for correspondence Hiok Yang Chan, MBBS, Department of Diagnostic and Interventional Radiology, Singapore General Hospital, Singapore (e-mail: hiokyang@gmail.com).

\begin{abstract}
Keywords

- May-Thurner syndrome

- stent

- thrombolysis

May-Thurner syndrome (MTS) is rare condition thought to occur due to an anatomical variation. In MTS, there is left iliac vein compression by the right iliac artery and lumbar spine resulting in left lower limb deep venous thrombosis. The authors report a rare cause of MTS postarterial intervention. They describe the unusual case of an Asian man who presented with acute left lower limb deep venous thrombosis 5 days following left common iliac artery angioplasty and stent insertion. Computed tomographic (CT) venogram demonstrated the left iliac vein compression by the left iliac artery stent. Successful recanalization of the thrombosed iliac vein was achieved with a combination of pulse spray thrombolysis and rheolytic mechanical thrombectomy, followed by angioplasty and stent placement in the iliac vein. There was rapid and complete resolution of symptoms. This report illustrates the use of complementary imaging modalities and a multidisciplinary team approach to achieve a successful technical and clinical outcome following an unusual case of MTS postarterial intervention and the subsequent successful endovascular management.
\end{abstract}

\section{Introduction}

May-Thurner syndrome (MTS), an infrequent cause of left lower limb deep venous thrombosis (DVT), occurs due to the right common iliac artery (CIA) overlying and compressing the left common iliac vein (CIV) against the lumbar spine. ${ }^{1-3}$ Most patients are asymptomatic. When symptomatic, they present acutely with unilateral leg swelling or pain that improves with elevation and worsens with prolonged standing. The main risk factors include prolonged immobilization and surgical interventions for gynecological and abdominal conditions. ${ }^{4,5}$ MTS is a rare cause of lower limb DVT.

We present a case of MTS following endovascular treatment of a left $\mathrm{CIA}$ occlusion and review the current available literature on this rare occurrence.

\section{Case Report}

A 57-year-old Asian man presented with symptoms of worsening claudication and rest pain (Rutherford IV class) of 1-week

received

February 4, 2019

accepted after revision

February 25, 2019

published online

July 18, 2019 duration. He had decreasing claudication distance to 15 to $20 \mathrm{~m}$ and new-onset rest pain, requiring increasing amounts of analgesia. He was a chronic smoker with cardiovascular comorbidities including diabetes mellitus, hypertension, hyperlipidemia, ischemic heart disease, and peripheral vascular disease. His blood investigations were normal. Pre-procedure duplex ultrasound study revealed an occluded left CIA and focal chronic wall-adherent thrombus in the left external iliac vein (EIV). Computed tomographic (CT) angiogram confirmed the duplex ultrasound results of a left CIA occlusion.

The patient underwent an uneventful left CIA angioplasty and primary stenting with $7 \times 37 \mathrm{~mm}$ Life Stream balloon-expandable stent (Bard). The left CIA occlusion was crossed subintimally via a retrograde femoral artery access. Prior to deployment of the balloon-expandable stent, the occlusion was predilated with a 5-mm Mustang balloon (Boston Scientific Corporation) to aid passage of the stent delivery system through the occluded segment. Manual compression was used to achieve hemostasis of the femoral artery access. The patient's critical limb ischemia symptoms Radiology
(C)2019 by Indian Society of

Vascular and Interventional

\section{License terms}

$10.1055 / \mathrm{s}-0039-1693630$

ISSN 2457-0214. 
improved post-procedure, and he was discharged home with dual antiplatelet therapy for 1 month. Five days post-procedure, he was readmitted with acute left lower limb swelling and pain. His left thigh and calf were edematous in keeping with phlegmasia alba dolens (-Fig. 1). Duplex ultrasound showed extensive acute DVT involving the left CIV, EIV, common femoral vein (CFV), and superficial femoral veins (SFV), as well as the below-knee deep veins. There was extensive thrombosis of the long saphenous vein and partially thrombosed in the calf ( $\mathbf{- F i g}$. 2a-e). On CT of the pelvis, the left CIV caliber was focally effaced where it traverses the stented left CIA and lumbar spine. The extensive iliofemoral DVT began upstream to the point of venous compression adjacent to the iliac artery stent, with thrombus seen extending into the inferior vena cava (IVC). The constellation of findings was

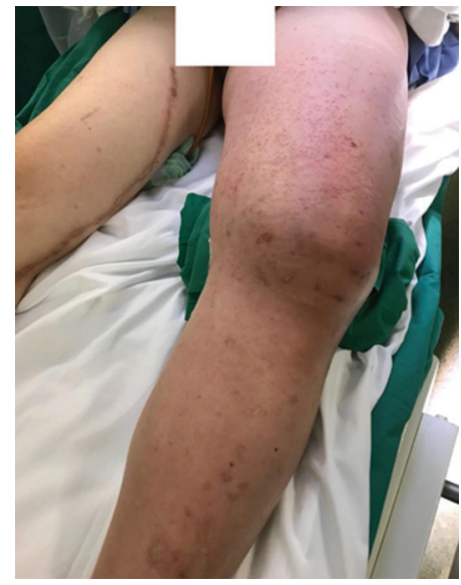

Fig. 1 Left lower limb phlegmasia alba dolens. suggestive of MTS. In view of acute extensive DVT, the patient was proceeded for early endovascular treatment (-Fig. 2f).

On-table ultrasound showed occlusion of the left CFV, SFV, and below-knee deep veins. As such, decision was made to obtain intravenous access via the left popliteal vein (PV) where a $10 \mathrm{~F}$ vascular sheath was inserted. Intraoperative venogram demonstrated extensive intravenous thrombus in the PV, CFV, and SFV (-Fig. 3a). After insertion of COOK Celect IVC filter (Cook Medical) via transjugular access, the patient underwent pulse spray thrombolysis (10 mg rTPA; 35 minutes dwell time) and rheolytic mechanical thrombectomy with 8F Zelante DVT Angiojet peripheral thrombectomy
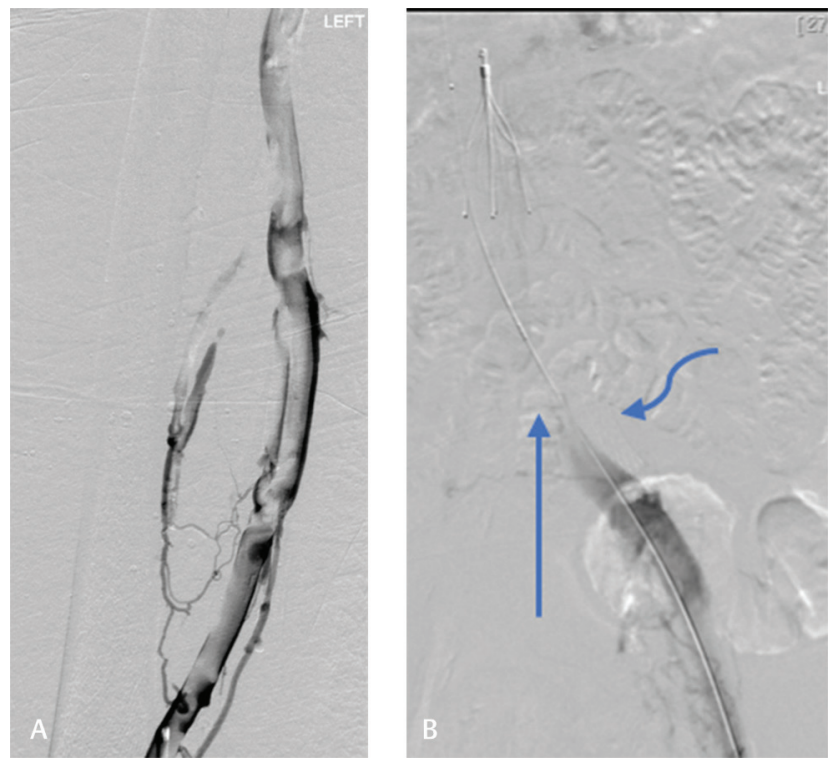

Fig. 3 Intraoperative venogram demonstrated extensive intravenous thrombus in the PV, CFV, and SFV.
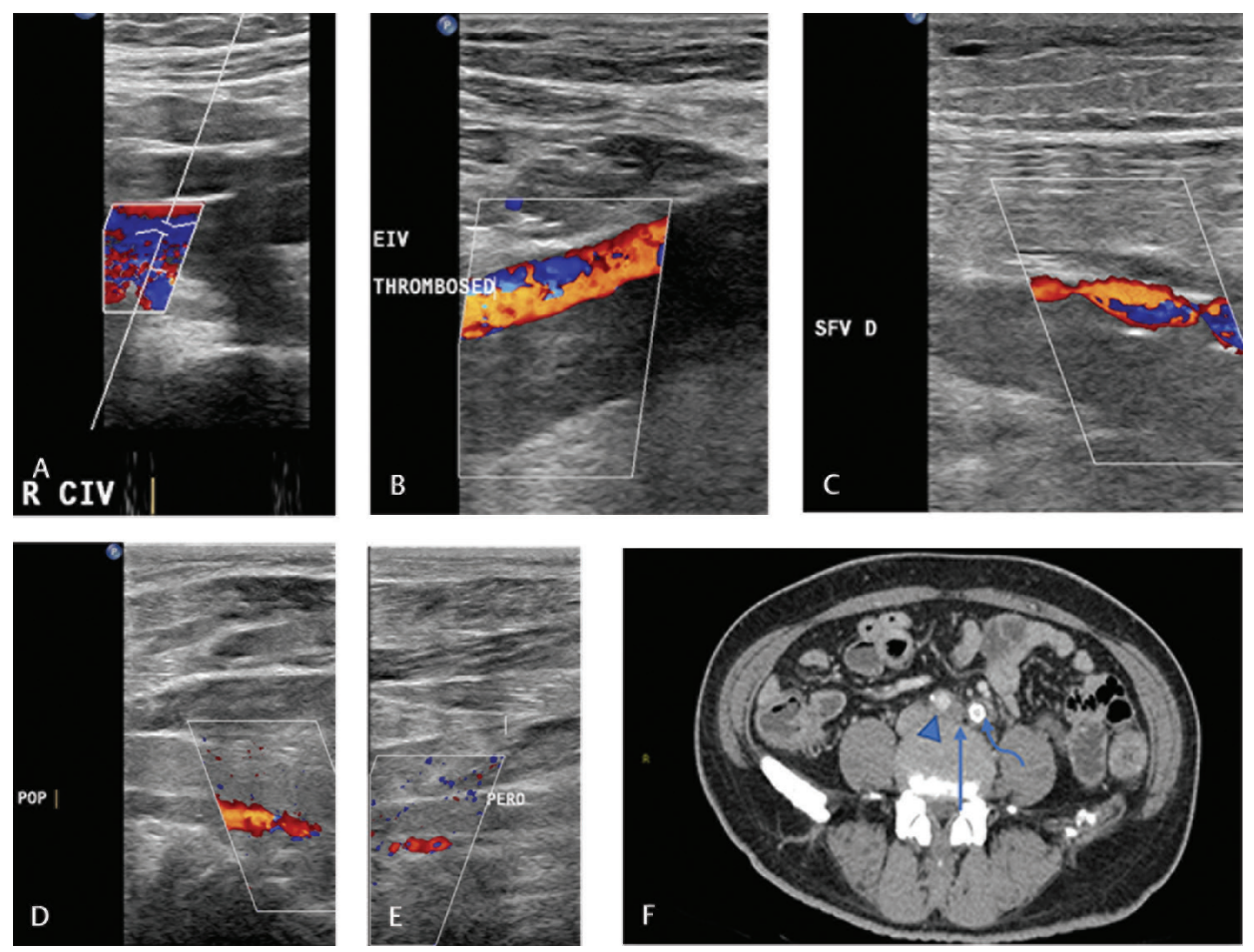

Fig. 2 Acute DVT involving the left CIV, EIV, common femoral vein (CFV), and superficial femoral veins (SFV), as well as the below-knee deep veins. 
system (Boston Scientific Corporation) of the thrombosed left iliofemoral veins. Intravascular ultrasound (IVUS) and catheter venogram confirmed the iliac vein stenosis at the level of the CIA stent ( $\mathbf{- F i g}$. $\mathbf{3 b}$ ). IVUS was also used to guide the aforementioned thrombus removal.

After clot removal, angioplasty of the left CIV was performed with $16 \times 40 \mathrm{~mm}$ ATLAS balloon catheter (BARD Peripheral Vascular), followed by stenting of the left CIV with $16 \times 100 \mathrm{~mm}$ Sinus-Obliquus stent (Optimed) and post-dilated with the same ATLAS balloon. There was uninterrupted in-line contrast flow from the PV through the CIV upon completion of the procedure (-Fig. 4a). Intravenous ultrasound demonstrated venous patency showing increased patent intravenous area in the left CIV (Figs. 4b, c).

This was subsequently confirmed on duplex ultrasound post-procedure showing a patent stent in the left CIV with complete recanalization of all the deep and superficial left lower limb veins (-Figs. 5a-e). There was immediate improvement in left lower limb swelling post-procedure and complete resolution of symptoms on discharge ( - Figs. 6a, b).

Postoperatively, the patient was commenced on therapeutic low-molecular-weight heparin (LMWH) (Clexane), thromboembolic deterrent (TED) stockings, and calf pumps. A thrombophilia screen performed to exclude an underlying prothrombotic tendency was negative. The patient was discharged with antiplatelet therapy.

\section{Discussion}

May-Thurner syndrome, otherwise known as iliac vein compression syndrome, was first described by May and Thurner in $1957 .{ }^{1}$ They found that the left CIV developed focal vascular thickening at the point where the overlying right CIA crossed it. Cockett and Thomas also reported the relationship between iliac vein compression and postthrombotic syndrome, and hence this condition is also known as "Cockett syndrome." ${ }^{2}$

Risk factors for MTS include female sex, immobilization, contraceptive use, trauma, postpartum period, contraceptive therapy, gynecological, and abdominal surgery. ${ }^{3,6}$ The MTS prevalence is estimated to be between 18 and $49 \%$ of patients presenting with lower extremity DVT.7 However, it is likely an underestimation as most patients are asymptomatic. Though venography and IVUS are the most sensitive
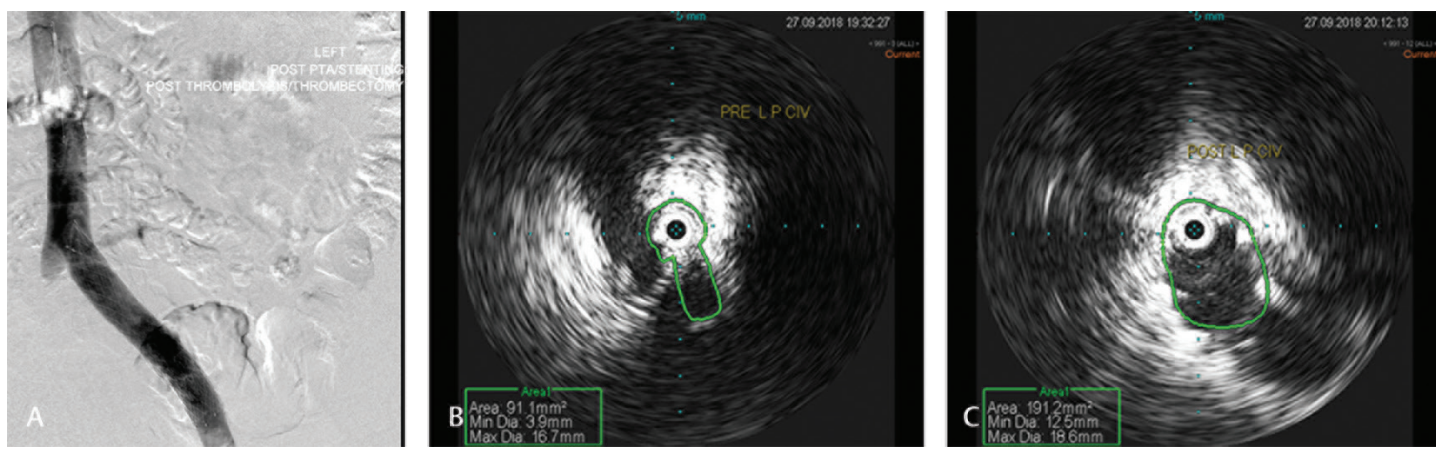

Fig. 4 Uninterrupted in-line contrast flow from the PV through the CIV upon completion of the procedure.
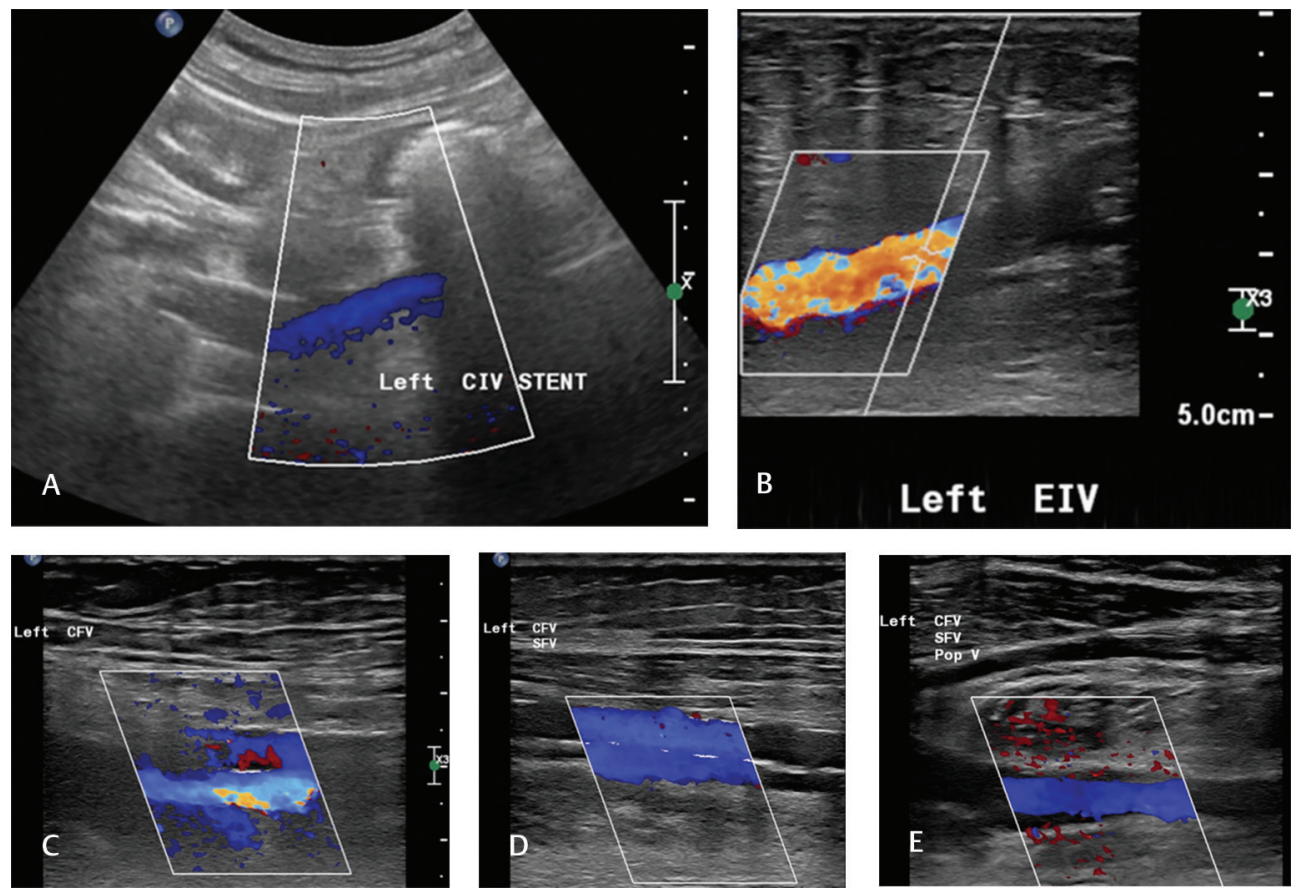

Fig. 5 Duplex ultrasound post-procedure showing a patent stent in the left CIV with complete recanalization of all the deep and superficial left lower limb veins. 

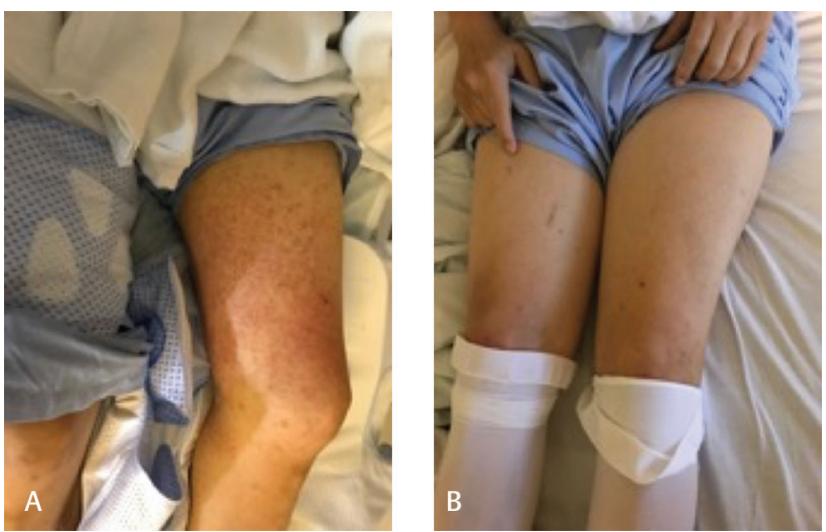

to prophylactically anticoagulate the patient with LMWH in the immediate postarterial interventional period until the patient was able to completely mobilize. This could have reduced the risk of precipitating propagation of venous thrombosis.

May-Thurner syndrome postarterial interventions have previously been described in the literature (-Table 1). The clinical presentation of patients who develop provoked MTS depends on the type and location of the extrinsic compression. Symptom onset may occur days to years after surgery and either CIV may be compressed. ${ }^{16-20}$

Our case highlighted the importance of being cognizant to this rare but potentially devastating complication that

Fig. 6 Improvement in left lower limb swelling post-procedure. can present days following the index procedure. This case

Table 1 Previous literature on provoked MTS post-procedure

\begin{tabular}{|l|l|l|l|}
\hline Author & Demographics & Precipitating procedure & Management and outcome \\
\hline $\begin{array}{l}\text { Young et al } \\
(2017)\end{array}$ & 60-year-old man & $\begin{array}{l}\text { Right CIA and EIA stenting } \\
\text { causing right CIV and EIV } \\
\text { thromboses. }\end{array}$ & $\begin{array}{l}\text { Stenting of right CIV and EIV with } \\
14 \times 60 \text { mm Wallstent (Boston Scientific, } \\
\text { Marlborough, Massachusetts, United States) } \\
\text { was deployed with complete resolution of } \\
\text { symptoms and no recurrence. }\end{array}$ \\
\hline $\begin{array}{l}\text { Pandit et al } \\
(2014)\end{array}$ & 65-year-old man & $\begin{array}{l}\text { Endovascular aortic stent place- } \\
\text { ment extending to bilateral distal } \\
\text { CIA causing left CIV thrombosis. }\end{array}$ & $\begin{array}{l}\text { Angioplasty of left CIV with } 18 \times 40 \text { mm } \\
\text { atlas balloon and stenting with } 14 \times 60 \text { mm } \\
\text { Luminex self-expanding stent. There was } \\
\text { complete resolution of symptoms and no } \\
\text { recurrence. }\end{array}$ \\
\hline $\begin{array}{l}\text { Hermany et al } \\
(2016)\end{array}$ & 75-year-old woman & $\begin{array}{l}\text { Bilateral CIA stenting causing left } \\
\text { CIV thrombosis. }\end{array}$ & $\begin{array}{l}\text { Stenting of left CIV with } 14 \times 60 \text { mm Wall- } \\
\text { stent. There was complete resolution of } \\
\text { symptoms and no recurrence. }\end{array}$ \\
\hline $\begin{array}{l}\text { Woo et al } \\
(2016)\end{array}$ & 65-year-old woman & $\begin{array}{l}\text { Pedicle screw from a prior L2-S1 } \\
\text { spinal fusion perforated through } \\
\text { L5 vertebral body impinging the } \\
\text { posterior aspect of the left CIV. }\end{array}$ & $\begin{array}{l}\text { Stenting of left CIV with } 14 \times 60 \text { mm } \\
\text { Wallstent. } \\
\text { There was complete resolution of symptoms } \\
\text { with no evidence of in-stent stenosis. }\end{array}$ \\
\hline
\end{tabular}

Abbreviations: CIA, common iliac artery; CIV, common iliac vein; EIV external iliac vein; MTS, May-Thurner syndrome.

investigations, they are often underutilized due to their invasive nature. ${ }^{8-10}$

Computed tomography venogram is the optimal noninvasive imaging modality for diagnosis but can also be used for posttreatment monitoring. ${ }^{11,12}$ Choi et al reported $92.9 \%$ predictive accuracy of CT venogram for identifying venous occlusion within 6 months of catheter-directed thrombolysis. ${ }^{11}$ IVUS has the added advantage of correlating age of thrombus, identifying collateral formation and measuring intravenous pressures in addition to ensuring accurate guidewire and stent placement during endovascular treatment. ${ }^{10,12,13}$

Treatment options include endovascular or open surgical procedures. Anticoagulation with open thrombectomy has been proven ineffective with a high rate of recurrence. Surgery is reserved for patients who fail endovascular therapy. Endovascular therapy has become the mainstay of treatment for MTS and involves catheter-directed-thrombolysis and angioplasty, followed by stent insertion. ${ }^{3,7,14-16}$

In this case, our patient had a duplex ultrasound study that demonstrated nonocclusive thrombus in the left external iliac vein. In hindsight, this finding could have alerted us illustrates the successful multidisciplinary team approach between vascular surgeons, vascular interventional radiologists, and hematologists, drawing experiences from different specialties to attain a positive outcome. This case also highlights the role of invasive and noninvasive imaging modalities to diagnose and treat MTS.

\section{Conclusion}

Our report highlights the use of complementary imaging modalities and a multidisciplinary team approach to achieve a successful technical and clinical outcome following a rare case of MTS postarterial intervention. The authors are of the opinion that endovascular specialists should be cognizant of this rare but important cause of lower limb DVT and familiarize themselves with effective endovascular management techniques as described in this report.

\section{Conflicts of Interest}

On behalf of all authors, the corresponding author states that there is no conflict of interest. 


\section{References}

1 May R, Thurner J. The cause of the predominantly sinistral occurrence of thrombosis of the pelvic veins. Angiology 1957;8(5):419-427

2 Cockett FB. The iliac compression syndrome alias 'iliofemoral thrombosis' or 'white leg.' Proc R Soc Med 1966;59(4):360-361

3 Mousa AY, Abu Rahma AF. May-Thurner syndrome: update and review. Ann Vasc Surg 2013;27(7):984-995

4 Campsen J, Bang TJ, Kam I, Gupta R. May-Thurner syndrome complicating left-sided renal transplant. Transplantation 2010;89(7):904-906

5 O'Sullivan GJ. The role of interventional radiology in the management of deep venous thrombosis: advanced therapy. Cardiovasc Intervent Radiol 2011;34(3):445-461

6 Raju S, Owen SJr, Neglen P. Reversal of abnormal lymphoscintigraphy after placement of venous stents for correction of associated venous obstruction. J Vasc Surg 2001;34(5):779-784

7 Kasirajan K, Gray B, Ouriel K. Percutaneous AngioJet thrombectomy in the management of extensive deep venous thrombosis. J Vasc Interv Radiol 2001;12(2):179-185

8 Raju S, Neglen P. High prevalence of nonthrombotic iliac vein lesions in chronic venous disease: a permissive role in pathogenicity. J Vasc Surg 2006;44(1):136-143, discussion 144

9 Meissner MH, Gloviczki P, Comerota AJ, et al; Society for Vascular Surgery; American Venous Forum. Early thrombus removal strategies for acute deep venous thrombosis: clinical practice guidelines of the Society for Vascular Surgery and the American Venous Forum. J Vasc Surg 2012;55(5):1449-1462

10 Forauer AR, Gemmete JJ, Dasika NL, Cho KJ, Williams DM. Intravascular ultrasound in the diagnosis and treatment of iliac vein compression (May-Thurner) syndrome. J Vasc Interv Radiol 2002;13(5):523-527

11 Choi JW, Jae HJ, Kim HC, et al. CT venography for deep venous thrombosis: can it predict catheter-directed thrombolysis prognosis in patients with iliac vein compression syndrome? Int J Cardiovasc Imaging 2015;31(2):417-426

12 Knuttinen MG, Naidu S, Oklu R, et al. May-Thurner: diagnosis and endovascular management. Cardiovasc Diagn Ther 2017;7(Suppl 3):S159-S164

13 Neglén P, Raju S. Intravascular ultrasound scan evaluation of the obstructed vein. J Vasc Surg 2002;35(4):694-700

14 Igari K, Kudo T, Toyofuku T, Jibiki M, Inoue Y. Surgical thrombectomy and simultaneous stenting for deep venous thrombosis caused by iliac vein compression syndrome (May-Thurner syndrome) Ann Thorac Cardiovasc Surg 2014;20(6):995-1000

15 Knipp BS, Ferguson E, Williams DM, et al. Factors associated with outcome after interventional treatment of symptomatic iliac vein compression syndrome. J Vasc Surg 2007;46(4):743-749

16 Pandit AS, Hayes M, Guiney-Borgelt S, Dietzek AM. Iatrogenic May-Thurner syndrome after EVAR. Ann Vasc Surg 2014;28(3):739.e17-739.e20

17 Young L, Kwon J, Arosemena M, Salvatore D, DiMuzio P, Abai B. Symptomatic compression of right iliac vein after right iliac artery stent placement. J Vasc Surg Venous Lymphat Disord 2017;5(5):735-738

18 Hermany PL, Badheka AO, Mena-Hurtado CI, Attaran RR. A unique case of May-Thurner syndrome: extrinsic compression of the common iliac vein after iliac artery stenting. JACC Cardiovasc Interv 2016;9(5):e39-e41

19 Reddy D, Mikhael MM, Shapiro GS, Farrell T. Extensive deep venous thrombosis resulting from anterior lumbar spine surgery in a patient with iliac vein compression syndrome: a case report and literature review. Global Spine J 2015;5(4):e22-e27

20 Woo EJ, Ogilvie RA, Krueger VS, Lundin M, Williams DM. Iliac vein compression syndrome from anterior perforation of a pedicle screw. J Surg Case Rep 2016;2016(2):rjw003 